\title{
Therapeutic Interventions for Tone Abnormalities in Cerebral Palsy
}

\author{
Ann H. Tilton \\ Louisiana State University Health and Sciences Center, New Orleans, Louisiana 70112
}

\begin{abstract}
Summary: Cerebral palsy (CP) is a common cause of movement disorders in children. The upper motor neuron syndrome of CP leads to several types of muscle overactivity, including spasticity. Reduction of muscle overactivity may be an important treatment goal, to improve comfort, care, and active function and to prevent future musculoskeletal complications. After a comprehensive team evaluation, a treatment plan is gener-
\end{abstract}

ated. Treatments may include physical and occupational therapy, oral medications, botulinum toxin and/or phenol injections, intrathecal baclofen, selective dorsal rhizotomy, and orthopedic surgery. Successful and early prevention of contracture may reduce the need for later corrective surgery. Key Words: Cerebral palsy, spasticity, botulinum toxin, intrathecal baclofen, selective dorsal rhizotomy, orthopedic surgery.

\section{INTRODUCTION}

Cerebral palsy (CP) is the most common movement disorder in children, occurring in 2-3 of every 1000 live births. ${ }^{1}$ It is significantly more common in lower-birthweight infants, and half of all cases occur in infants with a birthweight of less than a kilogram. ${ }^{2}$ The definition of $\mathrm{CP}$ has recently been updated by The Executive Committee for the Definition of Cerebral Palsy. ${ }^{3}$ Previous definitions focused exclusively on $\mathrm{CP}$ as a motor disorder, as in the 1978 definition by Nelson and Ellenberg, ${ }^{4}$ in which CP is "characterized by aberrant control of movement or posture of a patient, appearing early in life (secondary to a CNS lesion, damage or dysfunction), and not the result of a recognized progressive or degenerative brain disease." The recent update retains the emphasis on the motor disorder, but adds the likelihood that the patient will also have other impairments, which may be equally or more significant:

"Cerebral palsy $(\mathrm{CP})$ describes a group of disorders of the development of movement and posture, causing activity limitation, that are attributed to non-progressive disturbances that occurred in the developing fetal or infant brain. The motor disorders of cerebral palsy are often accompanied

Address correspondence and reprint requests to Ann H. Tilton, M.D., Children's Hospital of New Orleans, 200 Henry Clay Ave, New Orleans, Louisiana 70118. E-mail atilto@aol.com. by disturbances of sensation, cognition, communication, perception, and/or behavior, and/or by a seizure disorder."

Thus CP is a group of movement disorders that have in common that they are caused by static injury to the developing brain. The definitive diagnosis can only be made after a period of observation in which no progression of symptoms is observed, and any worsening of motor function over time indicates a different diagnosis must be sought. The child with CP may also have significant nonmotor impairments, including communication, intellectual function, learning disabilities, epilepsy, and sensory impairment. This article focuses on the treatment of the movement disorder aspects of CP.

Despite the high prevalence of CP compared with many other neurologic disorders, relatively little research has been done on its prevention and treatment. This is perhaps partly from funding priorities being driven by the more vocal proponents for other disorders, but also because $\mathrm{CP}$ encompasses a heterogeneous group of etiologies and wide variation in clinical presentation. Even standardized terminology for the clinical aspects of the disorder has been lacking, making comparisons of populations and outcome measures problematic. Some progress in this areas has recently been made by the Task Force on Childhood Motor Disorders. ${ }^{5}$ This NIH-supported effort developed detailed operational definitions of spasticity, dystonia, and rigidity, which are applicable to clinical features of hypertonic movement disorders in 
TABLE 1. Classification of Movement Disorders in Cerebral Palsy

Spastic
Diplegia: legs more involved than arms
Quadriplegia: all four extremities equally involved
Hemiplegia: one-sided involvement, usually arm more
than leg
Double hemiplegia: arms involved more than legs,
usually asymmetrical
Dyskinetic
Hyperkinetic or choreoathetoid
Dystonic
Ataxic
Mixed

children and which may aid in developing better inclusion criteria and outcome evaluations in future trials. A further problem in $\mathrm{CP}$ research is the difficulty of conducting blinded, placebo-controlled trials in this disorder. Such trials are the norm for oral medications, in which it is easy to mask the identity of the active drug and the placebo. Structuring such trials is far more problematic for other types of interventions, including physical therapy (PT) and surgery, yet these are currently (along with botulinum toxin injections) the most common and beneficial interventions in CP. Randomization without blinding is the alternative, and this methodology is commonly used in this population. In addition to the problems of structure, trials of surgical or PT interventions may be arduous, far more so than a comparable test of an oral medication. Performing such trials is difficult, and the clinicians and families who participate deserve a great deal of credit.

As an upper motor neuron disorder, $\mathrm{CP}$ gives rise to both positive and negative symptoms. ${ }^{6}$ The positive symptoms include muscle overactivity and increased deep tendon reflexes, while the negative ones are weakness and loss of fine motor dexterity. In general, only the positive symptoms are amenable to pharmacologic therapy. Unfortunately, in many cases the negative symptoms have the greater effect on patient function.

\section{EVALUATION AND TREATMENT}

Along with a revised definition of $\mathrm{CP}$, The Executive Committee for the Definition of Cerebral Palsy also recently proposed an updates classification scheme, ${ }^{3}$ which includes motor abnormalities, associated impairments, anatomic and radiologic findings, and causation and timing. In this scheme, the movement disorder is classified as spastic, dystonic, athetotic, ataxic, or mixed. ${ }^{7}$ Classification by anatomic distribution is based on affected body regions or specific type of movement and may include bulbar or trunk involvement as well as the canonical descriptions of limb involvement (Table 1). ${ }^{7}$ Motor abnormalities are also described in terms of their functional impact, ideally using one or more objective functional scales. Associated impairments are classified as present or absent, and, if present, their functional impact is assessed with standard tools.

Spasticity is defined as an increase in velocity-dependent tonic stretch reflexes with exaggerated tendon jerks. " $^{8}$ "Spasticity" is often used to encompass all forms of muscle overactivity, although Mayer and Herman 9 have pointed out that spasticity is only one type of muscle overactivity in the upper motor neuron syndrome. Others include clonus, flexor spasms, cocontraction, and dystonia. "Dystonia" is defined as a movement disorder in which involuntary, sustained, or intermittent muscle contractions cause twisting and repetitive movements, abnormal postures, or both. ${ }^{5}$ Cocontraction of agonists and antagonists sets the stage for rigidity, characterized by resistance at very low velocities of movement, absence of return of the limb to a fixed posture or angle, and lack of synergistic movement about the joint caused by movement in distant muscle groups. ${ }^{5}$ The distinctions between these various forms of overactivity may be more than academic, as some forms may respond more to certain medications than to others. To date, little research has been done with these distinctions in mind, making it difficult to test this hypothesis.

Spasticity per se can be roughly quantified in the clinic with the Modified Ashworth scale, a six-point measure of limb resistance to passive movement (see Table 2). The Modified Ashworth scale has been widely used as an endpoint in clinical trials; has the advantage of being simple to administer; and, with training, can be a reproducible measure for determining the efficacy of an intervention. It is, however, important for the clinician to distinguish resistance because of spasticity from resistance because of fibrotic changes in the muscle, which will not be amenable to pharmacologic interventions.

TABLE 2. The Modified Ashworth Scale for Evaluating Resistance to Passive Stretch in an Isolated Muscle Group

0 No increase in muscle tone

1 Slight increase in muscle tone, manifested by a catch and release or by minimal resistance at the end range of motion when the part is moved in flexion or extension/abduction or adduction, etc.

$1+$ Slight increase in muscle tone, manifested by a catch, followed by minimal resistance throughout the remainder (less than half) of the ROM

2 More marked increase in muscle tone through most of the ROM, but the affected part is easily moved

3 Considerable increase in muscle tone, passive movement is difficult

4 Affected part is rigid in flexion or extension (abduction or adduction, etc.)

$\mathrm{ROM}=$ range of motion.

Adapted from Ref. 10. 
The goal of treating muscle overactivity in $\mathrm{CP}$ is to improve some aspect of care, comfort, or active function and to prevent future musculoskeletal complications such as contracture and hip subluxation. Thus, treatment must begin with a comprehensive evaluation by a team that includes a pediatric neurologist, physical therapist, occupational therapist, social worker, education specialist, and other professionals, who together develop a complete picture of the child in the home and school environment. Working with the family, the team develops a treatment plan that considers current abilities and disabilities, child and family goals, limitations such as finances and transportation, and other factors. Within the overall treatment plan, reduction of muscle overactivity will likely become an important strategy but should never be an end in itself.

Physical therapy and regular physical activity form the basis of every treatment program. Oral medications may have a role in global tone reduction, although the concern for cognitive side effects is likely to limit their use. Injections of botulinum toxin or phenol provide focal tone reduction. Intrathecal baclofen may be appropriate for patients with significant and widespread muscle overactivity, especially in the lower extremities. Selective dorsal rhizotomy may be an option for patients with good underlying strength. Early treatment with any of these therapies may reduce the need for later orthopedic surgery.

\section{PHYSICAL THERAPY}

The goal of the PT program is to develop strength, maintain range of motion, and improve coordination while engaging the child in activities he or she naturally enjoys. Maintaining the full range of motion in tight muscles is of paramount importance, to prevent development of contracture. This can often be accomplished by a reasonably active child through normal activities of play, but compensatory strategies and postures may prevent the full range of motion of some affected muscle groups. Thus, regular stretching continues to be required. This usually requires a parent to implement a stretching program, under the guidance of the physical therapist. Ensuring compliance with this program may be one of the major challenges of treatment in CP. If successful, it allows the therapist to devote more office time to other PT activities, which can lead to better progress in developing more complex motor skills. Stretching at least 1 min every $12 \mathrm{~h}$ is recommended. ${ }^{11}$ Other forms of PT may include hydrotherapy and horseback riding ${ }^{12}$ and modalities such as biofeedback, heat, cold, and electrical stimulation. $^{13}$

Constraint-induced therapy (CIT) is an old technique undergoing significant renewed interest for children with hemiplegia. This resurgence is based partly on the grow- ing understanding of the brain's plasticity and stems from good results in adult stroke patients. ${ }^{14}$ The basic technique is to prevent the patient from using the "good" upper limb to perform functional tasks by constraining its movement. This forces the impaired limb to take over, greatly increasing its use and presumably "rewiring" the brain to work around the damaged motor control region. A recent trial by Taub et al. ${ }^{15}$ indicates its potential in $\mathrm{CP}$, but also the challenges of incorporation into the therapeutic program. Eighteen children with hemiparesis (ages 7 months to 8 years) were randomly assigned to CIT or conventional PT. Constraint was applied for $6 \mathrm{~h}$ per day for 21 consecutive days. After treatment, children undergoing CIT acquired significantly more new classes of motor skills (9 versus 2 ) and had more and better-quality movements of the affected arm. Tested in the lab, these children used their affected arm in more than $50 \%$ of spontaneous motor tasks versus only $2 \%$ for those not receiving CIT. Benefits were sustained at 6 months. Despite these promising results, physical therapists and parents alike are well aware of the difficulty of imposing this type of rigorous program on a child, and it is not yet clear whether a less burdensome treatment program may be able to offer similar benefits. More research is clearly in order.

It is widely recognized that children with $\mathrm{CP}$ are often weak. Surprisingly, however, the need for strength training is much less appreciated, despite that increased strength can improve ambulation. ${ }^{16,17}$ Strength training can also provide psychological benefits in adolescents, leading to increased feeling of well-being and participation in school activities. ${ }^{18}$

Dynamic equinus is commonly treated with an anklefoot orthosis (AFO). Carlson et al. ${ }^{19}$ showed that AFOs can significantly increase ankle dorsiflexion at foot strike, a key measure of equinus, although no improvements in gait were seen. When equinus inhibits standing in the preambulatory child, an AFO may promote the sit-to-stand transition. ${ }^{20}$

Balance problems may be amenable to use of walking aids. A walker may aid the child with spastic diplegia, for whom posterior balance is a principal problem. If forward balance is also impaired, crutches may be required.

Serial casting to prevent fixed contracture has a long history in the treatment of CP but is not without controversy. In recent years it has often been replaced with or become an adjunct to botulinum toxin type A (BTX-A) injections. Several randomized controlled trials have compared the efficacy of casting alone, BTX-A alone, or both treatments together. Corry et al. ${ }^{21}$ showed that the two treatments were equally efficacious in reducing tone and improving ankle kinematics, although the BTX-A group had fewer side effects and maintained benefit slightly longer. Similarly, Flett et al. ${ }^{22}$ found BTX-A to 
be as effective as casting in reducing calf tightness, and it was preferred by parents for its convenience. Bottos et al. ${ }^{23}$ compared BTX-A alone to BTX-A plus casting and found that either treatment led to reduced tone, but that the combination produced longer-lasting effects on tone, standing, and gait. Kay et al. ${ }^{24}$ used the opposite design, comparing casting alone to the combination treatment for reduction of ankle equinus, and found no difference in the duration of casting required for treatment. Surprisingly, results were better and longer lasting for the casting-alone group. Finally, Ackman et al. ${ }^{25}$ compared BTX-A alone, casting alone (with BTX-A placebo), and combination treatment for dynamic equinus. BTX-A alone performed worst, providing no significant benefit at any time in ankle kinematics, stride length, or velocity, while both casting groups did improve.

\section{ORAL MEDICATIONS}

The principal oral medications used in the treatment of $\mathrm{CP}$ are benzodiazepines, baclofen, tizanidine, and dantrolene sodium. All tend to produce sedation and drowsiness, which often limits their use in children. Relatively few double-blind trials of these agents have been performed in the $\mathrm{CP}$ population, and many of the trials supporting the efficacy of these agents date back more than 20 years.

\section{Benzodiazepines}

The benzodiazepines facilitate transmission at GABA-A receptors, one of the principal types of inhibitory synapses in the CNS. This results in increased inhibition and reduces mono- and polysynaptic transmission. ${ }^{26}$ Diazepam is the most commonly used agent. Mathew et al. ${ }^{27}$ showed in a trial of 180 children that a bedtime dose of diazepam was more effective than placebo in improving daytime spasticity and range of passive movement without causing drowsiness. Early trials from the 1960s indicate diazepam's effectiveness in reducing spasticity, especially in younger children and those with athetosis. ${ }^{28,29}$ One trial of clonazepam has also shown antispasticity efficacy in the $\mathrm{CP}$ population. ${ }^{30}$

\section{Baclofen}

Baclofen is a GABA-B agonist. A single trial of oral baclofen in $\mathrm{CP}$ demonstrated superiority to placebo in reducing spasticity and improving passive and active limb movements. ${ }^{31}$ Despite the relative paucity of clinical support for its use, oral baclofen is frequently prescribed for children with $\mathrm{CP}$.

\section{Tizanidine}

Tizanidine is an $\alpha-2$ adrenergic agonist, which prevents the release of excitatory amino acids from spinal interneurons. ${ }^{26} \mathrm{~A}$ single Russian study of tizanidine indicates its utility for treatment of $\mathrm{CP}$, although the results are available in English only in abstract form, making it difficult to judge the full study design. ${ }^{32}$

\section{Dantrolene sodium}

This agent acts at the muscle, reducing calcium efflux and thereby decoupling excitation and contraction. Joynt and Leonard ${ }^{33}$ found no clinical benefit from treatment in $20 \mathrm{CP}$ children, despite physiologic evidence of muscle force reduction. In contrast, Nogen ${ }^{34}$ found that dantrolene was effective at reducing spasticity and was more effective than diazepam in some patients. Nogen also showed that a combination of the two could be even more effective than either alone. Chyatte et al. ${ }^{35}$ also showed that dantrolene improved spasticity, although with little improvement in activities of daily living.

\section{BOTULINUM TOXIN AND PHENOL INJECTIONS}

The introduction of botulinum toxin for the relief of focal muscle overactivity was a major advance in the treatment of CP. It was not the first agent used for chemodenervation; however, injections of phenol or ethyl alcohol were used to treat spasticity for several decades before the advent of BTX. The advantage of BTX is its highly predictable muscle-weakening effect versus the somewhat less predictable effects of the other two agents, the comparative ease of administration, and the potential for fewer and less permanent side effects.

\section{Botulinum toxin}

Pharmacology. There are seven serotypes of botulinum toxin, A through $\mathrm{G}$, all produced by the bacterium Clostridium botulinum. ${ }^{36}$ Each is a protease that cleaves one or more vesicle fusion proteins at the neuromuscular junction, thereby preventing release of acetylcholine and inducing muscle weakness. Each toxin differs in its exact target, duration of action, and toxicity. Two serotypes, A and B, are approved by the United States Food and Drug Administration, as well as by European regulatory agencies, for use in humans. Two commercial forms of type A are available worldwide: BOTOX from Allergan Inc. (Irvine, CA, USA) and Dysport from Ipsen Ltd. (Slough, UK). Only Botox is approved and marketed in the United States, for treatment of cervical dystonia, blepharospasm, hemifacial spasm, primary axillary hyperhidrosis, and strabismus. A third form is currently undergoing clinical testing in Europe. One form of type B is available, known as MyoBloc in the United States and NeuroBloc in Europe. It is approved for the treatment of cervical dystonia.

The measure of potency of BTX is the "mouse unit," defined as the quantity of toxin that causes death in $50 \%$ of mice of a defined weight and strain. ${ }^{36}$ Because of manufacturing and intrinsic molecular differences, units of the various commercial toxins are not equivalent. 
Rough conversions indicate that one Botox unit is approximately equal in potency to 4 Dysport units and 50 MyoBloc units. Because of differences in side effect profiles, no standard conversion among products has been widely accepted among expert injectors. Botox and Dysport are supplied as freeze-dried powders, which are reconstituted in sterile saline before use. MyoBloc is supplied as a solution, which may be diluted or used as supplied.

Clinical practice. The most appropriate candidate for BTX injection is a patient for whom the weakening of a limited number of muscles has the potential to provide meaningful benefit in care, comfort, or active function. BTX may be used with other treatments, such as oral medications or intrathecal baclofen, to provide focal tone reduction. BTX is injected directly into overactive muscle. Electromyography, electrical stimulation, or sonography may be used to guide injections in difficult-toreach muscles, while palpation is usually sufficient for superficial or prominent muscles. Clinical benefit is usually seen within several days, and the peak benefit occurs at approximately 4 weeks. ${ }^{36}$ Benefit gradually declines, typically requiring reinjection at 3-4 months. Injections more frequently than 3 months increase the risk for development of neutralizing antibodies, a major concern when BTX is used at the high doses needed to treat spasticity. Antibody development precludes further use of the same serotype toxin, but it is possible to switch serotypes, from A to B or B to A.

Dosing guidelines for use of Botox in pediatric spasticity have been proposed to aid injectors. ${ }^{37}$ Sponsored by WE MOVE, a not-for-profit movement disorders educational organization, these guidelines were developed by an international panel of experts in the treatment of pediatric spasticity and reflect their long experience in the use of this therapy in this population. The guidelines suggest starting and maintenance doses for each of the muscles most likely to be involved in the common clinical patterns in the upper motor neuron syndrome. The guidelines also recommend a total ceiling dose per injection visit of either 16 Units Botox per kilogram, or 400 Units, whichever is less, again to minimize antibody formation.

Clinical trials. BTX-A has been tested in more than 40 clinical trials in CP. Its ability to reduce spasticity in both the upper and lower limbs has been proven repeatedly. ${ }^{21-24,38-44}$ What is less definitely proven is its effect on function. ${ }^{37}$ Many clinicians believe the difficulty of demonstrating a functional benefit has more to do with the structure of trials and the deficiencies of measuring tools than with the drug itself. Measures that combine effects for the entire body may be inappropriate for detection of functional improvement in one small region, such as the hand, despite that the improvement provides a significant benefit to the child. The development of more targeted measures is currently underway, and preliminary results confirm the functional benefits clinicians have reported. ${ }^{23,39,40,42}$ For example, in a single-blind trial, Steenbeek et al. ${ }^{39}$ showed that BTX-A administered to the lower limbs allowed 9 of 11 subjects to significantly improve on 18 of 33 individually set goals for therapy. Fehlings et al. ${ }^{40}$ showed that BTX-A administered to the upper limb plus PT led to more significant improvement in self-care than PT alone.

\section{Phenol and ethyl alcohol}

The use of these two agents for focal spasticity reduction predates the introduction of BTX. They have largely been replaced by BTX, but they still can be useful, especially for very powerful muscles inadequately treated by recommended doses of BTX, or when cost is a concern or antibody resistance to BTX has developed. Both agents are injected directly adjacent to a motor nerve, either where it enters the muscle (motor nerve block) or at the branching of the nerve within the muscle (motor point block). ${ }^{45}$ Both types of injections require considerable skill on the part of the clinician and carry the risk of significant adverse effects, including muscle necrosis, vascular complications, and dysesthesias. Pain is more likely after treatment of a mixed nerve.

Most recent studies of these agents have been in adults, and therefore little modern literature is available to analyze their potential in children. Two recent studies have compared phenol treatment to botulinum toxin in CP. Wong et al. ${ }^{46}$ compared BTX-A to phenol in 27 ambulatory children with lower limb spasticity and gait dysfunction. Sixteen received BTX-A, and 11 received phenol motor point blocks. Gait analysis at 1 week before and 2 months after treatment showed superior results for BTX-A, with fewer adverse effects. In a retrospective study of 68 patients, most of whom had CP, Gooch and Patton ${ }^{47}$ showed that adverse effects from either treatment were infrequent and that using them in combination allowed many more muscles to be injected.

\section{INTRATHECAL BACLOFEN}

Delivery of baclofen to the intrathecal space (ITB) dramatically lowers the amount of baclofen administered. This dose reduction is possible because the drug is delivered in the direct proximity of overactive spinal synaptic connections, rather than systemically, thus significantly reducing the cognitive side effects that limit the utility of oral antispasmodics. ${ }^{48}$ Baclofen is delivered to the intrathecal space with the Synchromed infusion system (Medtronic, Minneapolis, MN, USA), consisting of a pump and drug reservoir implanted subcutaneously in the abdomen and a catheter inserted most commonly at the T11-T12 level. The pump is remotely programmable via an on-board computer and telemetry wand, 
linked to a laptop computer. The reservoir, which contains an alarm indicating low drug level, is refilled percutaneously, usually every $9-12$ weeks but up to 24 weeks under normal conditions. The appropriate candidate for ITB has lower extremity spasticity of 3 or greater on the Ashworth scale, indicating significant muscle overactivity. A bolus infusion is used as a screening tool, with a decrease in one unit on the Ashworth scale being the standard for proceeding in most centers.

Controlled clinical trials of ITB indicate its ability to reduce muscle overactivity and improve function over prolonged treatment periods. ${ }^{48-51}$ Potential benefits include reduced spasticity, easier care and transfers, and reduced pain. The effects on ambulation may be unpredictable, with some patients improving, others remaining unchanged, and others worsening. ${ }^{52}$ ITB may reduce the need for orthopedic surgeries to the lower limbs, according to a study by Gerszten et al. ${ }^{53}$ They studied 48 patients receiving pumps, of whom 28 had been recommended for but had not yet received orthopedic intervention. In 18 of 28 , surgery was not deemed necessary after the pump implantation because of reduction in lower extremity muscle overactivity.

ITB therapy does carry the risk for significant complications. Infection, pump malfunction, and catheter kinking or withdrawal are all important concerns. ${ }^{54}$ Lifethreatening drug withdrawal is a possibility, and families must be educated about this concern and how to recognize its symptoms. ${ }^{55}$ Baclofen overdose, because of programming error, is also a possibility. ${ }^{56}$

\section{SELECTIVE DORSAL RHIZOTOMY}

Selective dorsal rhizotomy (SDR) cuts overactive dorsal nerve rootlets, reducing aberrant afferent activity from muscle spindles and reducing spasticity. A lumbar laminectomy or laminoplasty is performed. Individual nerve rootlets from L4 or L5 to S1 are stimulated. Those giving rise to excessive muscle activity are severed. Typically 25 to $60 \%$ of nerve rootlets are cut.

Multiple controlled trials have demonstrated the ability of SDR to reduce lower limb spasticity and increase range of motion. ${ }^{57}$ Improvements have been seen in gross motor function, self-care, and gait. ${ }^{58,59}$ SDR plus PT has been shown in two trials ${ }^{60,61}$ to be superior to PT alone for improvement of gross motor function and range of motion, although a third trial ${ }^{62}$ found no extra benefit from SDR plus PT versus PT alone. The best candidates for surgery are children ages 3-7 years, with spastic diplegia, good trunk control, good leg strength, and isolated leg movements (i.e., leg movements without involuntary involvement of other limbs). ${ }^{63}$ Intensive postoperative PT is essential to mobilize the patient and to regain preoperative motor function.

Concern has been raised about an increased risk for scoliosis after SDR, because of the weakening effect of the procedure. Johnson et al. ${ }^{64}$ found a higher rate of spinal deformity in patients undergoing SDR than in historical controls, a finding echoed by Steinbok et al. ${ }^{65}$ Some evidence indicates SDR can delay or avoid the need for orthopedic surgery later. ${ }^{66}$

\section{ORTHOPEDIC SURGERY}

Despite best management, many children with $\mathrm{CP}$ will eventually require orthopedic surgery to correct fixed contracture. The most common sites of surgery are the heel cords for equinus or equinovarus, and the most common operation is tendon lengthening with or without transfer. Some optimism about the state of CP therapy comes from a longitudinal survey by Hagglund et al. ${ }^{67}$ They found that the rate of orthopedic surgery for contracture or skeletal deformity decreased from $40 \%$ for children born in 1990-1991 to 15\% for children born in 1994-1995, which they attribute to the advent of other therapies, specifically botulinum toxin, intrathecal baclofen, and rhizotomy. This study emphasizes the potential of early and comprehensive treatment of muscle overactivity to prevent later complications.

Acknowledgments: I thank Richard Robinson for expert editorial assistance in preparation of this manuscript.

\section{REFERENCES}

1. Surveillance of cerebral palsy in Europe: a collaboration of cerebral palsy surveys and registers. Surveillance of Cerebral Palsy in Europe (SCPE). Dev Med Child Neurol 42:816-824, 2000.

2. Pharoah PO, Platt MJ, Cooke T. The changing epidemiology of cerebral palsy. Arch Dis Child Fetal Neonatal Ed 75:F169-F173, 1996.

3. Bax M, Goldstein M, Rosenbaum P, Leviton A, Paneth N, Dan B, Jacobsson B, Damiano D. Proposed definition and classification of cerebral palsy, April 2005. Dev Med Child Neurol 47:571-576, 2005.

4. Nelson KB, Ellenberg JH. Epidemiology of cerebral palsy. $A d v$ Neurol 19:421-435, 1978.

5. Sanger TD, Delgado MR, Gaebler-Spira D, Hallett M, Mink JW. Classification and definition of disorders causing hypertonia in childhood. Pediatrics 111:e89-e97, 2003.

6. Mayer NH. Clinicophysiologic concepts of spasticity and motor dysfunction in adults with an upper motor neuron lesion. In: Spasticity: etiology, evaluation, management, and the role of botulinum toxin (Mayer NH, Simpson DM, eds), pp 1-15. New York: WE MOVE, 2002.

7. Russman BS, Tilton A, Gormley ME Jr. Cerebral palsy: a rational approach to a treatment protocol, and the role of botulinum toxin in treatment. Muscle Nerve Suppl 6:S181-S193, 1997.

8. Lance JW. Symposium synopsis. In: Spasticity: disordered motor control (Feldman RG, Young RR, Koella WP, eds), pp 485-494. Chicago: Yearbook Medical, 1980.

9. Mayer NH, Herman RM. Phenomenology of muscle overactivity in the upper motor neuron syndrome. In: Muscle overactivity in the upper motor neuron syndrome: the role of oral medications, a focus on dantrolene sodium (Mayer NH, Pierson SH, eds), pp 1-25. New York: WE MOVE, 2004.

10. Bohannon RW, Smith MB. Interrater reliablity of a modified Ashworth scale of muscle spasticity. Phys Ther 67:206-207, 1986.

11. Reimers J. Clinically based decision-making for surgery. In: The diplegic child evaluation and management (Sussman MD, ed), p 
151. Rosemont, IL: American Academy of Orthopedic Surgeons, 1991.

12. Benda W, McGibbon NH, Grant KL. Improvements in muscle symmetry in children with cerebral palsy after equine-assisted therapy (hippotherapy). J Altern Complement Med 9:817-825, 2003.

13. Dali C, Hansen FJ, Pedersen SA, Skov L, Hilden J, Bjornskov I, Strandberg C, Jette C, Ulla H, Herbst G, Ulla L. Threshold electrical stimulation (TES) in ambulant children with CP: a randomized double-blind placebo-controlled clinical trial. Dev Med Child Neurol 44:364-369, 2002.

14. Hakkennes S, Keating JL. Constraint-induced movement therapy following stroke: a systematic review of randomised controlled trials. Aust J Physiother 51:221-231, 2005.

15. Taub E, Ramey SL, DeLuca S, Echols K. Efficacy of constraintinduced movement therapy for children with cerebral palsy with asymmetric motor impairment. Pediatrics 113:305-312, 2004.

16. Damiano DL, Abel MF. Functional outcomes of strength training in spastic cerebral palsy. Arch Phys Med Rehabil 79:119-125, 1998.

17. Dodd KJ, Taylor NF, Graham HK. A randomized clinical trial of strength training in young people with cerebral palsy. Dev Med Child Neurol 45:652-657, 2003.

18. McBurney H, Taylor NF, Dodd KJ, Graham HK. A qualitative analysis of the benefits of strength training for young people with cerebral palsy. Dev Med Child Neurol 45:658-663, 2003.

19. Carlson WE, Vaughan CL, Damiano DL, Abel MF. Orthotic management of gait in spastic diplegia. Am J Phys Med Rehabil 76: 219-225, 1997.

20. Wilson H, Haideri N, Song K, Telford D. Ankle-foot orthoses for preambulatory children with spastic diplegia. J Pediatr Orthop 17:370-376, 1997.

21. Corry IS, Cosgrove AP, Duffy CM, McNeill S, Taylor TC, Graham HK. Botulinum toxin A compared with stretching casts in the treatment of spastic equinus: a randomised prospective trial. $J \mathrm{Pe}$ diatr Orthop 18:304-311, 1998.

22. Flett PJ, Stern LM, Waddy H, Connell TM, Seeger JD, Gibson SK. Botulinum toxin A versus fixed cast stretching for dynamic calf tightness in cerebral palsy. J Paediatr Child Health 35:71-77, 1999.

23. Bottos M, Benedetti MG, Salucci P, Gasparroni V, Giannini S. Botulinum toxin with and without casting in ambulant children with spastic diplegia: a clinical and functional assessment. Dev Med Child Neurol 45:758-762, 2003.

24. Kay RM, Rethlefsen SA, Fern-Buneo A, Wren TA, Skaggs DL. Botulinum toxin as an adjunct to serial casting treatment in children with cerebral palsy. J Bone Joint Surg Am 86A:2377-2384, 2004.

25. Ackman JD, Russman BS, Thomas SS, Buckon CE, Sussman MD, Masso P, et al. Comparing botulinum toxin A with casting for treatment of dynamic equinus in children with cerebral palsy. Dev Med Child Neurol 47:620-627, 2005.

26. Gracies JM, Nance P, Elovic E, McGuire J, Simpson DM. Traditional pharmacological treatments for spasticity. Part II: General and regional treatments. Muscle Nerve Suppl 6:S92-S120, 1997.

27. Mathew A, Mathew MC, Thomas M, Antonisamy B. The efficacy of diazepam in enhancing motor function in children with spastic cerebral palsy. J Trop Pediatr 51:109-113, 2005.

28. Holt KS. The use of diazepam in childhood cerebral palsy: report of a small study including electromyographic observations. Ann Phys Med [Suppl]:16-24, 1964.

29. Engle HA. The effect of diazepam (Valium) in children with cerebral palsy: a double-blind study. Dev Med Child Neurol 8:661667, 1966.

30. Dahlin M, Knutsson E, Nergardh A. Treatment of spasticity in children with low dose benzodiazepine. J Neurol Sci 117:54-60, 1993.

31. Milla PJ, Jackson AD. A controlled trial of baclofen in children with cerebral palsy. J Int Med Res 5:398-404, 1977.

32. Brin IL, Kurenkov AL, Gotlib VI. [The use of sirdalud in cerebral palsy in children]. Zh Nevrol Psikhiatr Im S S Korsakova 99:3033, 1999.
33. Joynt RL, Leonard JA Jr. Dantrolene sodium suspension in treatment of spastic cerebral palsy. Dev Med Child Neurol 22:755-767, 1980.

34. Nogen AG. Medical treatment for spasticity in children with cerebral palsy. Childs Brain 2:304-308, 1976.

35. Chyatte SB, Birdsong JH, Bergman BA. The effects of dantrolene sodium on spasticity and motor performance in hemiplegia. South Med J 64:180-185, 1971.

36. Brin MF, Aoki KR. Botulinum toxin type A: pharmacology. In: Spasticity: etiology, evaluation, management, and the role of botulinum toxin (Mayer NH, Simpson DM, eds), pp 110-124. New York: WE MOVE, 2002.

37. WE MOVE. 2005 Management of spasticity with botulinum toxin type A (BOTOX®) [Online], 2005. Accessed January 4, 2006.

38. Speth LA, Leffers P, Janssen-Potten YJ, Vles JS. Botulinum toxin A and upper limb functional skills in hemiparetic cerebral palsy: a randomized trial in children receiving intensive therapy. Dev Med Child Neurol 47:468-473, 2005.

39. Steenbeek D, Meester-Delver A, Becher JG, Lankhorst GJ. The effect of botulinum toxin type A treatment of the lower extremity on the level of functional abilities in children with cerebral palsy: evaluation with goal attainment scaling. Clin Rehabil 19:274-282, 2005.

40. Wallen MA, O'Flaherty SJ, Waugh MC. Functional outcomes of intramuscular botulinum toxin type $\mathrm{A}$ in the upper limbs of children with cerebral palsy: a phase II trial. Arch Phys Med Rehabil 85:192-200, 2004

41. Baker R, Jasinski M, Iag-Tymecka I, Michalowska-Mrozek J, Bonikowski M, Carr L, MacLean J, Lin JP, Lynch B, Theologis T, Wendorff J, Eunson P, Cosgrove A. Botulinum toxin treatment of spasticity in diplegic cerebral palsy: a randomized, double-blind, placebo-controlled, dose-ranging study. Dev Med Child Neurol 44:666-675, 2002

42. Fehlings D, Rang M, Glazier J, Steele C. An evaluation of botulinum-A toxin injections to improve upper extremity function in children with hemiplegic cerebral palsy. J Pediatr 137:331-337, 2000.

43. Sutherland DH, Kaufman KR, Wyatt MP, Chambers HG, Mubarak SJ. Double-blind study of botulinum A toxin injections into the gastrocnemius muscle in patients with cerebral palsy. Gait Posture 10:1-9, 1999.

44. Corry IS, Cosgrove AP, Walsh EG, McClean D, Graham HK Botulinum toxin A in the hemiplegic upper limb: a double-blind trial. Dev Med Child Neurol 39:185-193, 1997.

45. Gracies JM, Elovic E, McGuire J, Simpson DM. Traditional pharmacologic treatments for spasticity. Part I: local treatments. In: Spasticity: etiology, evaluation, management, and the role of botulinum toxin (Mayer NH, Simpson DM, eds), pp 44-64. New York: WE MOVE, 2005.

46. Wong AM, Chen CL, Chen CP, Chou SW, Chung CY, Chen MJ. Clinical effects of botulinum toxin A and phenol block on gait in children with cerebral palsy. Am J Phys Med Rehabil 83:284-291, 2004.

47. Gooch JL, Patton CP. Combining botulinum toxin and phenol to manage spasticity in children. Arch Phys Med Rehabil 85:11211124, 2004.

48. Albright AL, Barron WB, Fasick MP, Polinko P, Janosky J. Continuous intrathecal baclofen infusion for spasticity of cerebral origin. JAMA 270:2475-2477, 1993.

49. Rawlins PK. Intrathecal baclofen therapy over 10 years. J Neurosci Nurs 36:322-327, 2004.

50. Gilmartin R, Bruce D, Storrs BB, Abbott R, Krach L, Ward J, Bloom K, Brooks WH, Johnson DL, Madsen JR, McLaughlin JF, Nadell J. Intrathecal baclofen for management of spastic cerebral palsy: multicenter trial. J Child Neurol 15:71-77, 2000.

51. Van SP, Nuttin B, Lagae L, Schrijvers E, Borghgraef C, Feys P. Intrathecal baclofen for intractable cerebral spasticity: a prospective placebo-controlled, double-blind study. Neurosurgery 46:603609, 2000.

52. Gerszten PC, Albright AL, Barry MJ. Effect on ambulation of continuous intrathecal baclofen infusion. Pediatr Neurosurg 27: 40-44, 1997.

53. Gerszten PC, Albright AL, Johnstone GF. Intrathecal baclofen 
infusion and subsequent orthopedic surgery in patients with spastic cerebral palsy. J Neurosurg 88:1009-1013, 1998.

54. Murphy NA, Irwin MC, Hoff C. Intrathecal baclofen therapy in children with cerebral palsy: efficacy and complications. Arch Phys Med Rehabil 83:1721-1725, 2002.

55. Zuckerbraun NS, Ferson SS, Albright AL, Vogeley E. Intrathecal baclofen withdrawal: emergent recognition and management. $P e$ diatr Emerg Care 20:759-764, 2004.

56. Darbari FP, Melvin JJ, Piatt JH Jr, Adirim TA, Kothare SV. Intrathecal baclofen overdose followed by withdrawal: clinical and EEG features. Pediatr Neurol 33:373-377, 2005.

57. Steinbok P. Outcomes after selective dorsal rhizotomy for spastic cerebral palsy. Childs Nerv Syst 17:1-18, 2001.

58. van Schie PE, Vermeulen RJ, van Ouwerkerk WJ, Kwakkel G, Becher JG. Selective dorsal rhizotomy in cerebral palsy to improve functional abilities: evaluation of criteria for selection. Childs Nerv Syst 21:451-457, 2005.

59. Galarza M, Fowler EG, Chipps L, Padden TM, Lazareff JA. Functional assessment of children with cerebral palsy following limited (L4-S1) selective posterior rhizotomy-a preliminary report. Acta Neurochir (Wien) 143:865-872, 2001.

60. Wright FV, Sheil EM, Drake JM, Wedge JH, Naumann S. Evaluation of selective dorsal rhizotomy for the reduction of spasticity in cerebral palsy: a randomized controlled trial. Dev Med Child Neurol 40:239-247, 1998.

61. Steinbok P, Reiner AM, Beauchamp R, Armstrong RW, Cochrane
DD, Kestle J. A randomized clinical trial to compare selective posterior rhizotomy plus physiotherapy with physiotherapy alone in children with spastic diplegic cerebral palsy. Dev Med Child Neurol 39:178-184, 1997.

62. McLaughlin JF, Bjornson KF, Astley SJ, Graubert C, Hays RM, Roberts TS, Price R, Temkin N. Selective dorsal rhizotomy: efficacy and safety in an investigator-masked randomized clinical trial. Dev Med Child Neurol 40:220-232, 1998.

63. Engsberg JR, Ross SA, Park TS. Changes in ankle spasticity and strength following selective dorsal rhizotomy and physical therapy for spastic cerebral palsy. J Neurosurg 91:727-732, 1999.

64. Johnson MB, Goldstein L, Thomas SS, Piatt J, Aiona M, Sussman M. Spinal deformity after selective dorsal rhizotomy in ambulatory patients with cerebral palsy. J Pediatr Orthop 24:529-536, 2004.

65. Steinbok P, Hicdonmez T, Sawatzky B, Beauchamp R, Wickenheiser D. Spinal deformities after selective dorsal rhizotomy for spastic cerebral palsy. J Neurosurg 102:363-373, 2005.

66. Chicoine MR, Park TS, Kaufman BA. Selective dorsal rhizotomy and rates of orthopedic surgery in children with spastic cerebral palsy. J Neurosurg 86:34-39, 1997.

67. Hagglund G, Andersson S, Duppe H, Pedertsen HL, Nordmark E, Westbom L. Prevention of severe contractures might replace multilevel surgery in cerebral palsy: results of a population-based health care programme and new techniques to reduce spasticity. $J$ Pediatr Orthop B 14:269-273, 2005. 